\title{
Analysis and democracy: the antecedents of the deliberative approach of ecosystems valuation
}

\author{
Alex Y Lo \\ Griffith School of Environment, Griffith University, Gold Coast Campus, Parklands Drive, \\ QLD 4222, Australia; e-mail: alex.lo@griffith.edu.au
}

Received 30 April 2010; in revised form 15 February 2011

\begin{abstract}
As a political institution, open deliberation on public policy can enhance legitimacy and procedural justice. As a science, decision-aiding deliberative procedures can help overcome bounded rationality of individuals. Integrating the two modes of inquiry would be perfect for capturing the plural values of the environment. However, the analytic requirements seem to point in a different direction from the political ideals. Legitimacy problems arise when the supposedly unconstrained process is professionally 'guided'. But rigorous decision aids fail to work without some degree of cognitive guidance. A trend in ecosystems valuation research is the use of analytic techniques in the deliberative processes of value articulation. In this paper an analytic-deliberative approach is assessed against a deliberative democracy theory. This approach seeks to facilitate deliberation within individuals and to engineer preference towards instrumental rationality. The evaluative framework allows predetermination of the range of outcomes. Little room has been made for value debates, thus the moral need for actual discussion is weak. Being expert centred, the framework provides constricted spaces for empowerment. Alternative expressions unintelligible to the science may be put at a disadvantage. The scope for a reflexive democratic institution appears limited. A promising deliberative valuation approach should be integrative, including analytic and political elements as complementary to each other, and should be democratic in its production.
\end{abstract}

\section{Introduction}

Science and democracy are equally important for engaging decision makers with the plurality of environmental values. Integrative efforts at conjugating behavioural science and democratic theory have drawn considerable attention from policy researchers and economists. This is evidenced by the rising prominence of the use of deliberative methods in economic valuation research. However, not all deliberative institutions are democratic. Behind this deliberative turn we see a clash of democratic and scientific principles in relation to public participation.

Recent advancements in ecosystems valuation research include deliberative monetary valuation (DMV) (Spash, 2007; 2008). It involves the use of formal group processes in environmental value assessment, which is traditionally treated as a scientific exercise. In the processes participants are confronted with various perspectives concerning the functions and their perceptions of ecosystem goods or services. They undertake group discussions on these perspectives and the assessment tasks, prior to stating group or individual willingness-to-pay figures concerning a resource allocation decision. This deliberative turn has been influenced by two intellectual currents. Deliberative experiments that are informed by behavioural science and decision analysis focus on human cognition barriers (Gregory, 2000; Gregory et al, 1993). Political theorists, on the other hand, appeal to democratic theories and accentuate fairness and institutional issues (Douai, 2009; Jacobs, 1997; Niemeyer and Spash, 2001; Sagoff, 1998).

DMV practitioners see the two strategies as equally important. Most of them employ one to complement the other, and many believe that only an integrated approach could provide a viable alternative to the conventional valuation methods (Howarth and Wilson, 2006). This is because the failure of conventional practice is 
twofold - that is, lacking insights into people's cognitive constraints and the plural values they hold. Decision scientists, who consider monetary valuation tasks cognitively demanding, advocate the use of more decision aids as a scientific procedure to support the value articulation process. Some of them recognize the potential of public deliberation in allowing information sharing and raising democratic legitimacy. Political theorists generally accept the use of decision support to enhance participants' competency. They contend that the key function of public deliberation is to civilize behaviours (Jacobs, 1997). In both cases, deliberative procedures are introduced to enable some civic virtues.

Although deliberative procedures have been used for similar reasons, the two approaches differ in terms of the priority of the political ideals, concerning the degree of participant empowerment, format of deliberation, and type of arguments allowed. To decision scientists, participatory initiatives need more analytic rigour, and a good valuation needs more science. Analytic expertise beyond usual facilitation skills is given a central role in producing considered decisions.. To deliberative democrats, fair procedures are of primary importance, and a good valuation practice requires more democracy from the processes of value articulation as well as theorization. The latter entails a paradigm shift to postpositivism entailing self-critical, internally democratic scholarly norms (Norton and Noonan, 2007). The new science calls into question the prevalent notion of value neutrality of scientists and endeavours to unfold values ahead of building models. This resonates to the concept of postnormal science which has come to the forefront of environmental research (Funtowicz and Ravetz, 1993). Nevertheless, it may stand at variance with the conventional practice, where research quality is assessed by the objective truth-seeking scientific standards. The tension raises concern as to the feasibility of integrating the analytic and political procedures.

DMV practitioners are at pains to meet the requirements of decision science and deliberative democracy at the same time (Lo and Spash, 2011). Spash (2008) and Jorgensen (2009) are unconvinced by the current practice that some practitioners have failed to provide consistent explanations and properly address value pluralism. One of the possible reasons pertains to the science-democracy conflict. Mainstream economists are expected by their peers to strictly follow traditional scientific rules and are tempted to build their deliberative innovations upon a constricted agenda in accordance with given decision or economic principles. The democratic principles being called for, however, may pose a challenge to their professional sovereignty and the established research practice dominated by positivism. The democratic ideal that participatory evaluation should put the use of experimental controls at a minimum and maintain a distance from predefined scientific rules does not appear attractive to those economists who pursue scientific rigour.

The economists and also decision analysts defend that such a process could still achieve democratic goals to some degree (eg, McDaniels et al, 1999; Macmillan et al, 2006). I argue that a deliberative approach could be considered democratic only if its design is defensible in terms of deliberative democracy theory. A deliberative valuation is far from pluralistic to the extent that the inquirer's predispositions excessively constrain a supposedly fair and equal communicative process. The democratic quality can be assessed in terms of the openness of the processes of value articulation and theorization. An examination in this light is needed to endorse an analytic-political hybrid.

In this paper I assess the democratic potential of an analytic-deliberative model. The inquiry is intended to inform a debate regarding the use of deliberative methods in monetary valuation of the environment and to support a forthcoming paper on DMV 
(Lo and Spash, forthcoming). It is to study the theoretical antecedent of a specific analytic DMV approach identified in that paper, which was not exhaustively elaborated. So the scope of analysis of this paper is restricted. More attention is paid to the deliberative designs as used by decision analysts.

The ways in which public deliberation is defined by deliberative democracy and decision science theories are first elucidated. A comparison is made to highlight conceptual variations. The challenge of incorporating deliberative elements into decision analysis is then discussed. The implications to the pursuit of value pluralism conclude the paper.

\section{Conceptual elements of democratic deliberation}

The democratic deliberative approach emphasizes the issue of legitimacy and opportunities for dialogue. It is informed by the theory of deliberative democracy, which has been split into several theoretical traditions. For the present discussion, more attention is paid to Dryzek's (eg, 1990; 2000) work for his prominence in environmental politics and greater intellectual influence on the latest developments in ecological economics.

Deliberative institutions respond to deep conflicts and uncertainties. Pluralistic societies are characterized by the existence of diverging and irreducible values. Aggregative institutions have been used to settle the conflicts between them, often unsatisfactorily, by reducing moral decision to a preference calculus (Dryzek, 1990; 2000). These institutions privilege the needs of the greatest number, irrespective of reasonable partial interests. Maintaining such privilege, however, appears problematic in the face of increasing value diversity. Moreover, current preference politics and economics are ill equipped to deal with uncertainties. They are built upon the assumption that the individual has complete knowledge about his or her own preferences. Known social preferences allow decision makers to exercise instrumental rationality. When ecological uncertainties are considerable, their ability to cope with contingencies and model preferences is overwhelmed. The seemingly intelligent instrumental manipulation constrained by present states of knowledge is then called into doubt (Dryzek, 1987). Therefore, new institutions are needed to deal with value diversity and our limited ability to predict. Opportunities for deliberation enable people to prepare as far as possible for all implications.

The theory is rooted in the concept of communicative rationality (Dryzek, 1990). An action is communicatively rational to the extent that it is characterized by the reflective and intersubjective (ie, between individuals) understanding of the deliberating individuals on values, beliefs, and preferences (Habermas, 1984). The communicative interaction between individuals must be free from deception, strategic behaviours, and domination through exercise of power. Dryzek $(1990 ; 2000)$ argues that a democratic deliberation should not predispose the individuals to a particular set of beliefs beyond basic rights. With this feature it is classified as a second-order theory.

According to Gutmann and Thompson (2004, page 13), first-order theories, such as utilitarianism, seek to resolve moral conflicts by rejecting rival theories. Each theory claims to be the single theory capable of resolving conflicts, but does so in ways that deny or exclude its alternatives from consideration. Being a second-order theory, deliberative democracy is not exclusive. Second-order theories regulate first-order theories by providing ways of dealing with the conflict between them. They do not affirm or deny a priori moral principles expressed by first-order theories. First-order theories assume that citizens are destined for a particular moral end or require them to change their moral beliefs accordingly. Second-order theories govern their interaction by providing a set of standards and rules of conflict resolution. Citizens are required only to follow these standards and rules, but are not assumed to be pursuing specific 
moral ideals. In this light, democratic deliberation does not necessarily aim to induce citizens to change their held values, but to encourage diverse value positions to live with each other even if they are mutually incompatible.

Reason giving is the first and foremost requirement (Bohman, 1996; Cohen, 1989; Dryzek, 1990; 2000; Gutmann and Thompson, 1996). The mere fact of having a preference does not itself constitute a reason in support of a proposal in relation to a public decision (Cohen, 1989). Collectively binding laws and policies are justified by the adequacy of reasons given to other citizens, and not necessarily by how much preference could be satisfied.

The core activity of the deliberation is mutual justification mediated through the virtue of reciprocity. Reciprocal cooperation requires a citizen who engages in public deliberation give reasons that other free and equal citizens could reasonably accept, and could accept others' reasons in the same manner. Reciprocity is a moral basis for taking action under irresolvable disagreement. Deliberating individuals should bring forth and develop a sense of mutuality during the course of deliberation; they are expected to exercise mutually justifiable reasons and to pay respect to their counterparts, who may hold distinct dispositions and preferences. A desirable outcome is that they affirm the moral status of their own positions and acknowledge the legitimacy of those they oppose (Gutmann and Thompson, 1996). This ideal recognizes the civil demeanour of 'agreeing to disagree'.

Arguing on values is encouraged. Mere inclusion and elicitation of values are considered insufficient. The theory emphasizes the expression and assessment of values in linguistic forms of arguments, rather than votes. It is intended to promote persuasion attempts and enable the multiplicity of arguments to be recognized. Deliberating individuals are encouraged to perform holistic assessment and to determine acceptance in an intersubjective manner. These requirements imply that the deliberation should be formulated as a dialogue, where arguments could interact. The dialogue should "downplay 'centrism' of any kind" (Dryzek, 1995, page 18) - that is, privileging no single perspective.

An ideal outcome is an action agreement that is built upon respect for reasonable differences rather than universal appeals. The celebration of diversity in favour of universality has two implications. First, a deliberative democracy is indefinitely critical toward established interests and perspectives and should be free from coercive and manipulative forces from elites. Second, the theory confers a new political import to the concept of 'public opinion'. Rather than a personal choice made out of free will, public opinion is reconceptualized in terms of "the outcome of contestation" of discourses (Dryzek, 2000, page 50). In a deliberative democracy, democratic legitimacy should issue from the communication between various discourses in response to each other within the public sphere. Public opinion thus exists in the social and political interactions among individuals and groups, not within the minds of solitary thinkers.

Deliberative democrats are divided as to whether or not public deliberation should be destined for a consensus. Consensus democrats seek consensus through realizing a comprehensive common good, whereas pluralists seek to improve capacity for social cooperation under persistent value disagreements. To the pluralists, value disagreements cannot be overcome without some form of repression, and the deliberative project should aim at finding good ways of living with them. Simple consensus based on convergence of values is called into doubt.

One ideal deliberative outcome is 'workable agreement', which refers to agreement on a course of action yet for different reasons (Dryzek, 2000). It is advanced as a concept of 'meta-consensus' (Dryzek and Niemeyer, 2006). Normative meta-consensus requires agreement on the recognition of the legitimacy of a value. Citizens are not 
expected to agree on the priority of others' legitimate values, but to develop greater intersubjective understanding in the search for collective decisions that respect all legitimate basic values. From this perspective, the quality of a deliberative outcome is a function of the degree of mutual recognition between individuals in terms of expressed values.

\section{Analytic deliberation}

There is a large body of literature about analytic deliberation. However, this paper has a specific focus on those writers from the monetary valuation field, of whom the most prominent are Robin Gregory, a decision scientist, and his associates, ${ }^{(1)}$ who have contributed to the DMV literature (Gregory, 2000; Gregory and Wellman, 2001; Gregory et al, 1993; McDaniels et al, 2003). These DMV studies are inherited from their decision models that have been applied to group-based environmental assessment, which are therefore relevant to the present purpose. Another reason for this focus is that they illustrate the sharpest contrast to the political approach. Renn's (1999) model, for example, falls between the two extremes even though it is also called 'analytic deliberation'. (2) Other more balanced views include those of Proctor and Drechsler (2006), Burgess et al (2007), and the National Research Council (2008). It is not my intention to generalize the following discussion to these other models.

\section{Assumptions}

The proponents of analytic deliberation believe that individuals have limited cognitive ability for making complex decisions: "individuals (either lay or expert) will often not make informed, thoughtful choices about complex issues involving uncertainties and value tradeoffs" (McDaniels et al, 1999, page 498). People perform poorly in handling unfamiliar choices and technical information, which may create a high level of stress blocking rational routes of decision making (Arvai et al, 2001). Cognitive difficulties cause failures in expressing and clarifying multiple values. Community-based environmental initiatives fail simply because participating individuals refuse or do not recognize the complexity of the value dimensions and are not equipped to address the necessary trade-offs (Gregory, 2002).

A utilitarian conception of values is adopted. Multiattribute utility theory (MAUT) is applied, which assumes comparability and transitivity of preference relation, and allows complete substitution between subjective states. When explaining the theory, Gregory et al (1993, page 187) equate values to utilities and advocate utility maximization. Unlike neoclassical economics, the analytic approach goes beyond choice and involves its fundamental structure and motives. Arvai et al (2001), Gregory et al (2001), and McDaniels et al (1999) make reference to Keeney's (1992) theory of 'value-focused thinking', which suggests that consideration of values precedes that of available alternatives when individuals make decisions. This model construes value as a standard of hedonic satisfaction and ultimately aims to satisfy people's wants in an instrumental fashion:

"Value-focused thinking essentially consists of two activities: first deciding what you want and then figuring out how to get it... With value-focused thinking, you should end up much closer to getting all of what you want" (page 4).

(1) Those papers reviewed here include, but are not limited to, Arvai et al (2001), Failing et al (2007), Gregory (2000), Gregory (2002), Gregory and Failing (2002), Gregory and Gregory (2010), Gregory and Slovic (1997), Gregory et al (1993), Gregory et al (2001), Gregory et al (2005), McDaniels et al (1999).

(2) Renn (1999) understands analytic deliberation somewhat differently from Gregory and associates; he takes social justice more seriously and doubts the domination of expert judgment. In this paper, analytic deliberation mainly refers to Gregory's approach. 
Alternatively, value could be construed as a 'judgment' rather than 'interest' (Holland, 1997). Judgment concerns 'what ought to be' whereas interest concerns 'what we want'. An individual could make a judgment on something regardless of his or her immediate interest, but would want it only if it is in his or her interest. Keeney (1992) seems to embrace ethics and the idea of 'value judgments', but the recognition is largely limited to judgment on personal preferences, such as job choice (page 4). Preferences do not conflict, only judgments do (Holland, 1997). If 'what you want' included subjective judgment over other people's well-being, it would be a question of 'what ought to be'. 'Ought to' questions entail the virtue of justification to others, whereas 'want' questions do not.

Multidimensional considerations are encouraged. Given the irresolvable conflict between competing viewpoints, the conventional requirements of agreeing on values and seeking consensus are regarded as untenable (Failing et al, 2007; Gregory et al, 2001). However, a pragmatic treatment is needed to identify an acceptable course of action. The suggestion is to construct a common hierarchy where incommensurate values become indirectly comparable (Gregory, 2000; Gregory et al, 1993). Social cooperation is built upon the assumption that there is a state of affairs that people would accept as universal.

Value disagreement is considered a matter of perception rather than principle. It is attributed to the different ways of "interpretation of information" between individuals, rather than "differences in underlying values" (Gregory, 2000, page 157). Value integration then becomes possible by making different dimensions "transparent" and leading individuals to the "commonality of their beliefs" (page 157). The means to achieve this is simplification. A common language of values is employed to lessen individuals' cognitive burdens by reducing the dimensionality to a comprehensible summary.

Deliberation is given a supplementary role. Communication is circumscribed by and serves science: "[to] fill the important missing links in individuals' fragmentary scientific understanding" (Gregory et al, 2005, page 9). Democratic imperatives give way to decision science standards:

"In our view, risk management decision processes can be made more 'democratic', as the title of this piece 'Democratizing risk management' suggests, but only with a clear structure and a decision framework focusing on values, meaningful technical information, tradeoffs, and insight" (McDaniels et al, 1999, page 509).

The strong scepticism to unaided deliberation contributes to this view. The idea of redeeming popular participation by employing group deliberation is ridiculed as a "naive assumption" (Gregory et al, 2001, page 418). McDaniels et al (1999) contend that unaided collective thinking cannot help counter individuals' cognition problems, because it is vulnerable to the tendencies to establish entrenched positions and to adopt common perspectives leading to ignorance of contrary information. Self-designed, autonomous deliberation by lay people about environmental risk is described as "a recipe for disaster" (page 500). There is little room for an autonomous public to take issue with or modify the frame of analysis: "the scope of their role falls well short of a license to redesign the process" (page 500).

Group participants are expected to play only a passive role: "simply to report to the elected or appointed decisionmakers who are seeking input through the process what alternatives the various stakeholders can support" (page 501). More generally, "the objective of public involvement is to provide insight to decisionmakers, not to resolve a dispute" (page 508). Therefore, "one should never allow public involvement processes to actually set policy. Presumably that role should be reserved for legitimate government agencies or elected representatives" (page 499). 


\section{Strategy}

Value-articulating institutions are constructed as a "kind of tutorial" (Gregory et al, 1993, page 179), where analysts "look for trouble" such as "false fluency", which refers to respondents claiming that they understand a problem better than is actually the case (Gregory et al, 2005, page 13). The process seeks to mirror the ways in which individuals "naturally think"- thinking about benefits and costs systematically (Gregory, 2000, page 153). Expert instructions are provided to help participants go through a professionally designed learning scheme which imitates a human's natural cognitive process. The general strategy is to help participants break down their entangled value considerations into several dimensions. The starting point of assessment is their own held values through to weighing up required costs and benefits, leading to a choice that best fits given objectives. Since this calculative process requires systematic thinking while few individuals are natural systematic thinkers, the analysts believe that it must be led by decision experts.

Analytic deliberation facilitates self-exploration. The deliberative model fosters the weighing of benefits or costs and arguments in a mental dialogue. The participants were asked individually about their value dimensions with the reminder: "value dimensions are of different importance to different people. We want to know what is important to you" (Gregory, 2000, page 160, original emphasis). The decision steps of the "structured decision-making process" outlined in Failing et al (2007, page 51) are in principle achievable by solitary individuals. Communication as a group is not essential.

It is suggested that preferences should be corrected. The deliberation enables a constructive dialogue among participants, creating a 'legitimate forum' (Failing et al, 2007, page 53). The notion seems to be consistent with the principles of deliberative democracy. Yet, it requires the individuals while making decisions to articulate clear distinctions between treatments of facts and values (Gregory et al, 2005). Failing et al (2007, page 55) do not shrink from restricting their approach to fact-based dimensions. They claim that the aim is not to pit one validity claim against another, but to expose their differences and facilitate better understanding of the issue concerned. Participants are free to use affective and emotional expressions (Gregory, 2002), but "competing hypotheses" have to be justified on an "evidential basis" (Failing et al, 2007, page 54). Priority is given to expert knowledge. Validity claims made by lay participants are compared with expert beliefs to reveal "the critical gaps in lay understanding, thereby disciplining claims about the adequacy of lay comprehension" (Gregory et al, 2005, page 9, my emphasis). Failing et al (2007, page 57) admit that the communications are constrained by demanding that the participants articulate their concerns following a structured decision scheme with clear references made to scientific data concerning probabilities and consequences.

Analytic deliberation is oriented to practical tasks. Value disagreements are acknowledged, but fundamental value contest is deliberately avoided. In a report of a water-use planning issue, Failing et al (2007, page 56) suggest that:

"On the values side, participants often enter a deliberative process highly polarized.

Asking for value statements such as 'what's more important, drinking water quality or ecological health?' or 'how do you feel about toxic waste?' is unlikely to lead to anything but divisive positioning. A key role of knowledge in a decision-oriented process is to distinguish among the relative merits of proposed actions. Unless participants are focused on the practical task of deciding not just the positivist question of what is, but also the normative question of what to do about it, it is possible to spin endlessly in technical and philosophical debates that prove ultimately to be largely irrelevant for management." 
The deliberation is focused on clarification of facts and a search for practical solutions. A 'normative' question is understood as a pragmatic one - that is, 'what to do about it'. This offers an alternative interpretation of the earlier democratic pledge that local knowledge and cultural values have to be critically assessed. By critical, it actually means objective scrutiny based on evidence and facts rather than on moral merits. A good analytic deliberation is defined in terms of its capacity to deepen participants' understandings. The focus on 'analysis' suggests an orientation to the technical and informational dimensions of risk characterization.

\section{Procedure}

Analytic deliberation involves a schematized process of clarifying values which needs "technical guidance" (Gregory, 2002, page 476). All procedures are designed for making 'unavoidable' value trade-offs. Gregory argues that making value trade-offs is psychologically challenging, but the tension can be eased by addressing them head on. Trade-offs are not deemed as inherently irresolvable, provided that they are adequately clarified and made explicit by following the value-focused model (Arvai et al, 2001).

The optimism can be explained by the analysts' understanding of values. First, they speak of value conflict in terms of technical incommensurability, which "refers to the issue of representation of multiple identities in descriptive models" (Munda, 2006, page 91). Value is regarded as an expression of wants, which can be expressed in various formats. Conflict is attributable to the use of incompatible formats, or "unlike attributes"; an example is choosing between incremental levels of "more guns or more butter", which is a creating a "confusing type of choice" (Gregory, 2002, page 486). Alternative attributes should be adopted as the expression formats are considered independent of the real utility function. Thus natural and constructed metric are suggested for easing trade-offs. Rights-based beliefs are understood as a result of exercising "simplistic decisions rules (eg, any loss, however small, of a valued resource is prohibited)" to "escape" from hard trade-offs (page 11). Such trade-offs can evoke affective responses when individuals adopt these rules, and may create confrontations between them. Cognitive aids are used "to defuse such confrontations" by "stabilizing" emotions (page 11).

Second, value belongs to the personal domain. Making informed value trade-offs are accordingly viewed as a solitary affair largely based on individual introspection. Gregory's (2002, page 467) solution - that is, “addressing people's concerns headon"-deals with internal conflict within one's own mind. Deliberating individuals are required to justify their trading off morality or principles only before themselves. They succeed to the extent that they feel satisfied, regardless of whether or not the choice would be actually justifiable or acceptable to others. These authors might defend that analytic deliberation contains group discussion elements making room for this. However, as revealed throughout all their works, group discussion plays merely a supplementary role of facilitating information sharing and exposing differences. Mutual justification is not a necessary requirement to get a policy option passed, and utility points are assigned as an individual decision. The critical decision moment is to a large extent free from mutuality. The toughest issue is avoided-namely addressing one's choice in terms of the world view of one's rivals.

Values are elicited using a disaggregation procedure. A complex issue is broken down into several dimensions each linked to an 'end objective', such as 'ecological health', which are then further reduced to a set of 'means objectives', such as fish and wildlife conservation. By considering their more 'tangible' constituents, the hard-to-define spiritual and cultural values are made recognizable and included into evaluation. Then, participants may be asked to individually express their preferences 
by assigning 'importance points' to each performance measure. This makes possible conversion of perceived importance of one dimension in terms of another one, including to equivalent dollars so long as one of the dimensions is expressed in dollar terms (Gregory, 2000). The use of this natural or constructed metric as a neutral unit could avoid provocative forms of value expressions such as the dollar. Participants are not directly asked to substitute their held values for something incompatible, but indirectly so. This could avoid "the unnecessary controversy" involved in trading off protected values (Failing et al, 2007, page 57). Psychologically, expressing importance is less challenging than evaluating a loss. Trade-offs are made explicit but are framed in a different way.

The overall importance for each option is calculated by aggregating the importance points assigned. The levels of aggregate preference for all the policy alternatives then become visible and comparable. The analytic approach claims to facilitate learning to compare and make choice through focused calculative procedures presented in a decision-friendly way. These procedures mainly serve and regulate individuals instead of groups.

Arvai et al (2001) assess the quality of a deliberative decision according to three dimensions: participants' satisfaction, diversity of issues discussed, and improvement in knowledge. The first and third dimensions are assessed by the participants while the second dimension is assessed by the research team. Either way, these measures operate at an individual level. By these assessment standards, it is possible for a process of analytic deliberation to be judged as effective, even if it involves merely solitary thinkers with adequate decision supports and a supply of relevant information. Assessment of communicative dynamic is not given priority despite the title "deliberative risk communication" (Arvai et al, 2001). Another measurement is time consistency of preferences. Properly aided deliberations could change values and preferences, and preferences ideally would remain roughly stable after the process. Again, the assessment focus is individual rationalization.

Another set of assessment criteria concerns the extent to which accepted standards of decision analysis, which policy debates often lack, are met (Gregory et al, 2005). McDaniels et al (1999) stress that decision quality depends more on a right decision framework than on the right people or the right information, suggesting the importance of procedural scientificness over fairness. The other assessment criteria offered by McDaniels et al (1999, pages 507-09) pertain to quality of recommendations and cost-effectiveness. From this perspective, a good public participation initiative is one that can provide useful insights to decision makers and satisfactorily meet the given objectives at reasonable cost.

\section{A comparison}

Table 1 summarizes and compares the core features of the two approaches. Analytic deliberation involves an expert-led learning process for engineering preferences by providing cognitive aids. Participants in need of education are required to adjust to the expectations of the science. Under the rubric of democratic deliberation, participants are idealized as autonomous political agents charged to assess the merits of alternative proposals. They are given more room to reorganize the deliberative processes and, in effect, execute some of the deliberative principles.

Analytic deliberation aims at facilitating instrumental considerations and promotes logically consistent, systematical, and efficient ways of value expression. In democratic deliberation, mutual recognition is regarded as a meaningful outcome. Although the democrats favour a set of political ideals, it is not destined for a comprehensive moral end, from which a course of action in relation to resource allocation could be deduced 
Table 1. Comparison of analytic and democratic deliberation.

Analytic deliberation

Democratic deliberation

\section{Assumptions}

Policy challenge

Conception of value

- ontological foundation

- dimensionality

- comparability

- source of value disagreement

Participatory democracy

- role of democracy

- relationship with science

- role of the public

\section{Strategy}

Analogy

Imitation

Organization

Reflection

Primary goals

\section{Procedure and validation}

Degree of behavioral intervention

Decision steps

Value elicitation

- treatment

- formal expression pathway

Assessment criteria

- for participants

- for procedure and outcome

cognitive inability of individuals

irreducible moral conflict

monistic
multiple
strong
different ways of information
$\quad$ interpretation

secondary

aided by science

provide insights

\section{tutorial}

natural cognitive processes

expert led

introspective

correct preference and deepen case understanding

\author{
high \\ clarify values, think broad, \\ make rational trade-offs
}

disaggregation and aggregation via natural or constructed metrics
self-assessed levels of satis- faction and knowledge gain; internal stability of preference procedural scientificness; quality of recommendations

\author{
pluralistic \\ multiple \\ weak \\ competing ethical principles
}

\section{primary}

scrutinize science

provide insights and/or make decisions

\section{dialogue}

political/social interactions participant-oriented intersubjective

contest preference and deepen mutual understanding

\section{low}

justify values, think broad, determine acceptability

\section{holistic assessment} via speech

level of reciprocity; interpersonal consistency of preference procedural fairness and openness; meta-consensus

from various options. There is little presumption of universal acceptance beyond basic rights. On the contrary, the analytic-deliberative approach takes utility maximization as such an end. Like neoclassical economics, therefore, it rests on the principle of impartiality.

Furthermore, value plurality is handled in different ways. Behind analytic deliberation is the philosophy of value reductionism - that is, decomposing decision into smaller elements for isolated consideration. The democratic deliberative approach is not necessarily incompatible with moral integration, but it is not a necessary criterion of good decision making. Differences in reality perceptions are not to be reduced for the sake of pragmatic needs. Reasoned differences are considered an acceptable outcome. 


\section{The democratic potential of analytic deliberation}

The theories of deliberative valuation emerge as an interface where science and democracy come into conflict. Some decision science principles appear at variance with those of deliberative democracy. Three interrelated inconsistencies are identified, concerning the organizing principle, value pluralism, and evaluation focus, respectively.

\section{The fallacy of impartial deliberation}

Enforcing an impartiality principle could displace the need for actual communication. The analytic approach seeks utilitarian compensation by replacing a multicriteria problem for a monocriterion one with a single valued function, replacing incomparable options for analytically comparable ones, and denying preference thresholds. The use of MAUT may excessively change the nature of the problem at hand unnecessarily (Munda, 1995).

Analytic deliberation has different democratic qualities from democratic deliberation. Deliberative opportunities are used to advance case-related knowledge composed of "fact-based inputs (what is) and value-based inputs (what ought)" (Failing et al, 2007, page 50). It is believed that value questions need clarification rather than refutation:

"Exploration of value-based knowledge (priorities and preferences) on the other

hand, must focus on seeking clarification and understanding rather than corroboration or refutation.... The quality of a value claim will be related to clarity, consistency and explicitness" (page 50).

It is doubtful that normative questions about public goods, concerning the wellbeing of other people or species, can be satisfactorily answered merely by clarifying knowledge content. To settle such a what-ought-to question, one must either justify his or her claims or refute others' claims. The question is a matter of judgment rather than preference (Holland, 1997). Convincing justification and refutation must go with reasons which in principle could be rejected even if sufficiently clarified. Clarification attempts not prepared to be challenged belong to a preference-type question, rather than a what-ought-to question. If a clarification attempt requires acceptance from a second party, it would become a kind of justification and turn the discussion to a value debate.

Yet, analytic deliberation is actually a programme of demonstration, although 'justification' is stated at various points. The principle of impartiality requires a process of demonstration whereas reciprocity requires deliberation (Gutmann and Thompson, 1996). It relies on objective evidence and factual information to enable the individuals to see which policy option is the best according to the universally acceptable criteria. Analytic deliberation fits squarely to this notion. This is evidenced in its emphasis of 'evidential basis' and 'clarification', and scepticism to opening 'philosophical debates' and 'unnecessary controversy' (Failing et al, 2007). Further proofs are evident in those general statements in favour of objectification of value expressions and scientific rationalization of public participation.

There is little room for value debates and the normative question of 'why to do'. It is then dubious to employ common democratic vocabularies such as "justifying knowledge claims", "to debate ... competing claims", "normative judgment", "legitimate forum", and "constructive dialogue ... about values" (Failing et al, 2007, various pages). 'Justification' has been understood as justifying the knowledge content of validity claims (demonstrating), which differs from justifying value content. The former is likely to be accepted upon perfect validation in objective terms, whereas the latter might still be rejected even so. To make an impartial public decision, policy makers need to do no 
more than collect the most credible evidence and demonstrate it to the public. This is all the justification it needs. There is no moral need for mutual justification and actual discussion. The merits of analytic deliberation diminish with the intensity of fundamental social conflict. This indicates a decisive deviation from the concept of deliberative democracy to which the opposite applies.

Democracy without value debate is problematic. With commensurability assumed and value debate avoided, what the analysts would need is simply a well-designed questionnaire and a computer, not group deliberation. Where deep moral conflict is at issue, analytic deliberation can hardly produce feasible agreements without compromising the deliberative democratic principles. Crafted along the lines of a hard science, it is trapped in a problem about value pluralism.

\section{The engineer mentality and the meta-democratic problem}

A function of analytic deliberation is exposing differences. However, not all positions are reasonable so that some of them should be excluded through democratic processes. Deliberative democracy demands that discursive space be sufficiently open and seeks reconciliation within deliberation. Analytic deliberation offers no decision principle that is exercised within deliberation to identify and exclude unqualified proposals. Otherwise, the deliberating individuals would have been allowed to reject other people's claims on acceptable grounds. Instead, they are led to merely learn from each other. Learning could be an uncritical experience without contestation. Thus, value contest is not encouraged and 'tutorial' is used as analogy.

The emphasis of evidential basis could be regarded as such a decision principle. However, its formulation and execution is external to the deliberative process from which legitimacy is sought. Value claims must be made measurable and articulated in universally acceptable and objective terms. The definition of these terms is circumscribed by the scope of decision analysis. Following Keeney (1992), Gregory and Failing (2002) devise a value-articulating framework based on three criteria - namely, measurability, operationality, and understandability. The strategy is not to empower participants to determine acceptability, but to determine acceptability on their behalf by limiting the discursive space a priori. Diverse perceptions of reality are reformulated in accordance with the predefined rules. Some aboriginal participants found these rules or instructions constraining (Failing et al, 2007, page 56).

A defending response is that uninformed, ignorant public may fall captive to interested stakeholders or agencies (Gregory et al, 2005). Gregory et al (page 7) add that " $[\mathrm{t}] \mathrm{o}$ create a better-informed public, the managers of deliberative processes must circumscribe the potentially relevant facts and set priorities among them." However, informing (forming) public will in this way, too, is open to manipulation. Manipulative intent might be hidden behind alleged scientific rigour. It is not uncommon that scientists supported by industrial or political organizations with vested interest are caught for selectively defining irrelevance and arbitrarily setting priorities in favour of a preferred agenda that could guarantee continuous support (Myhr, 2010; Nerlich, 2010; Spash, 2010). The top-down analytic approach is predisposed to a particular social state and problem definition which ought to be subject to a democratic process, thus raising a meta-democratic problem. Such preoccupations must be minimized to raise democratic potential.

Analytic deliberation embraces, in Anderson's (1993) terms, a secondary conception of value plurality which captures diverse authentic standards of evaluating qualities of goods. However, it falls short of a primary one based on a plurality of evaluative attitude by which goods are sensibly valued in different ways. This conception pertains to the extent to which goods are appropriately valued and may be independent of their 
meeting any authentic evaluative standard. With 'why' and 'ought' questions avoided, analytic deliberation fits well to the opposing monistic view that "all goods are the proper objects of a single evaluative attitude" (Anderson, 1993, page 4). Alternative evaluative modes are restricted. The reduction to a monocriterion decision may unnecessarily strip off some culturally specific ways of organizing value 'language' and preclude individuals from expressing ethical propositions based on moral conviction and emotion (Satterfield, 2001). Anecdotal forms of expressions and experiential differences in kind are put at a disadvantage.

Expert cultures could pose a threat to value pluralism (Spash, 2009). Failure to democratically elicit values limits the plurality expressed. Failing et al (2007, page 50) claim that some but not all science is reliable. Being strong advocates of decision science, presumably they believe that their science is reliable. This gives licence to applying restrictions to the agency of participants in validating the selected frame of analysis, let alone taking issue with the decision experts. The limited procedural flexibility has led to selective inclusion of agendas. Deliberative democrats hold that both deliberative design and even principles are redeemable in their own terms and that outcomes remain indefinitely provisional and revisable (Dryzek, 1990; 2000). Value pluralism is considered a concept to be publicly defined in a continuous fashion. The schematized analytic-deliberative framework requires values to be expressed in a particular shape compatible with some scientific predispositions.

Science itself offers a way by which to value things. Circumscribed within the scope of decision science, the range of values articulated is predetermined, paradoxically, by one kind of value meant to be openly debated. The incremental movement from one science (neoclassical economics) to another (decision science) offers minimal potential for value pluralism.

\section{Subject-centred evaluation}

A subject-centred view of public deliberation is tightly linked to serving the values and interests of individuals and groups (Renn et al, 1995). An option is chosen for its ability to satisfy the dominant values and interests. Renn et al (pages 7-8) contend that people's values and interests are nearly always diverse, so participatory process must have losers by any evaluative criteria. Philosophically, then, no evaluation could be justified over another. This view sees public participation as a zero-sum game. In practice, it is hard to not recognize certain justice principles as legitimate, such as equity and efficiency. Forcing people to accept only one side is likely to lead to a vicious cycle of conflict. It is better to interpret some social goals as demanding balance and recognition, such as religious pluralism and multiculturalism. These goals could be 'satisfied' only by simultaneously satisfying the preferences of competing groups, which seems hardly attainable given resource constraints. A better evaluative focus concerns people's interaction in which recognition of shared values and reasonable differences are realized. A subject-centred view gives little credit to the role of intersubjective communication in seeking fair terms of social cooperation.

Analytic deliberation promises informed individual thinking processes, whereas social interaction plays a minor role. Efforts at aiding decision are based on the satisfaction of values and interests of the individuals to the greatest extent. This makes little room for the virtue of mutual respect that could lead participants to recognize or agree on a course of action for reasons that deviate from their personal values or interests. The idea of 'workable agreement', based on varied values and interests and coordinated through communicative norms, is not taken as a criterion of ideal deliberative outcome. Choices divorced from one's well-clarified objectives would be discredited as a product of cognitive failure. A successful workable agreement might 
then be labelled as an inferior solution, because the decisions of at least some of the participants deviate from their own values and interests.

Under the analytic approach, value conflict is resolved not by striving for mutual acceptance or recognition, but indirectly by deriving an algorithmic solution from an aggregation of individual decisions. Attainment of intersubjective understanding is not taken as a criterion of success. With the algorithmic solution rationally arrived, a deliberation might be judged as successful, irrespective of the extent to which diverging participants appreciate rival viewpoints and mutually respect each other.

Merely enabling disagreeing individuals to speak and express preference does not constitute a sufficient condition for deliberative democracy. Of more importance is the capacity to listen, which is crucial to respecting irreducible diversity out of empathy. Gregory et al (2001) admit that analytic deliberation does not aim for conflict resolution. Where deep moral conflict is at issue, such a calculation-oriented deliberative approach might reach a rational decision without giving the suffered individuals adequate respect and motivation to genuinely cooperate or contribute to a collective action. The inadequacy of intersubjective encounters might deplete the moral qualities essential to a democratic state.

\section{Discussion and conclusion}

The analytic-deliberative approach has limited democratic qualities and scope for value pluralism. Attempts to utilize the hard science of decision analysis as well as to realize a deliberative democracy prove challenging. Nonetheless, this is not tantamount to advocating a replacement of analysis for lay judgment. Modest analytic innovations are crucial to help the individuals understand complex information.

The analytic-democratic tension is related to the nature of the public-good issues addressed. Analytic-deliberative strategies have been widely used in environmental risk assessment. Strictly structured and professionally aided deliberative strategies could ease the exhausting risk-related choices. Deliberative democracy, on the other hand, has greater potential for resolving morally charged social, cultural, or religious conflicts. Such conflicts stem from a clash of moral beliefs held to be inviolable rather than poor understanding of causal information. Fundamental values and procedural fairness are key factors. Environmental problems inevitably have various moral and technical issues entangled. Analytic approach alone can hardly satisfactorily respond to the moral challenge. Nonetheless, prompt actions are needed to prevent irreversible human-induced ecological changes from expanding and the deliberative democratic principles may be too ideal to guarantee timely agreement on a course of action. More compelling is to run the two as a complementary enterprise.

To explore complementary potential, researchers must pay attention to the project objective, the nature of the issue under evaluation, and practical constraints. Mechanical transfer of established knowledge to the other area is not sufficient. Analysis and democratic deliberation have competing propositions and assumptions concerning the means by which their objectives are met. The conflict could threaten the prospect for a competitive hybrid. Joint venture that combines their best features may end up reducing problem-solving capacities and offsetting added contributions. Under certain circumstances, analytic deliberation might become a distorted communication programme.

Notwithstanding the tension, it is not futile to find better ways of recognizing the reality of conflict and dealing with it authentically and democratically. Opinions, notions, and concepts come from complex internal divisions and external interpellations that operate in the minds of people. The methodological tension is a reflection of the actual value conflict in the society, illustrating an uncoordinated interaction 
of different rationalities and practical solutions. The tension between discursive communication and citizen empowerment, and structured analysis, mirrors the fact that a vibrant civil society consists of oppositional social forces inconsonant to bureaucratic and technocratic controls. As far as research practice is concerned, it is inappropriate and unrealistic to deliberately distance from this reality through demarcation or outranking, as the social meaning of any such discourse is in part derived from their antithesis. What is required is an intellectual conversation to authentically engage with the competing elements, rather than a pragmatic scepticism that unhelpfully views them as an inherent, regrettable dichotomy to be dealt with in the absence of the other. An analytic-democratic complementary enterprise should be treated as a reflexive, communicative activity between two intellectual traditions rather than a mechanical combination.

The project of deliberative valuation would be hopeless if it failed to recognize the linkage between value pluralism and democratization of science. The relation of democratic deliberation to postpositivism has gone unnoticed. Postpositivist inquiry demands democratic coordination on the part of inquirer, and not just the subject of inquiry. Subjects deliberate on values in a conceptual arena constructed by the valueladen inquirer. Of critical importance, then, is the issue of determining decision criteria behind the scene. The tension does not come as a group of 'objective' experts holding a knowledge toolbox struggling over competing techniques. It should be treated as their consciously engaging in the activity of problem definition where the inquirer comes to play the role of a subject of study interacting with his or her respondents. Thus there are two levels of democracy to be addressed.

A defensible theory of plural values is pluralistic from the very bottom; it has to be democratically theorized. Drawing on Dewey, Dryzek and Berejikian (1993, page 59) argue that the cure for the ailments of democratic theory is more democratic theorytheory that is democratic in its production, as well as its content. The democratic potential of a value-articulating institution is defined in terms of its production and hermeneutic activities, and not just in survey operation. Value pluralism does not tolerate a deliberate separation of reality construction activities by the value holders inquired from those by the inquirer.

An otherwise monolithic approach shaped by an expert culture should be held in suspicion. A technocratic or economistic deliberative design that subtly puts key democratic concepts at the periphery has limited democratic potential. The real challenge to DMV is not the practical difficulties arising from dealing with diversity, but elitist biases that enter the deliberative process unconsciously, unspoken, and unrecognized (O'Hara, 2001). A meta-discourse has to be extended to the backstage to expose specialists' preoccupations and interests. It entails a nonhierarchical communication and coordination among various research traditions in favour of a productive encounter among distinct intellectual perspectives. The 'architect-engineer' mentality should be avoided. Decision analysts and economists involving in DMV research have to balance such a mentality with the competing elements of the democratic theories they refer to. To make public deliberation democratic ultimately rests on an adequate awareness of their preoccupations about the nature of public value and measures against manipulative behavioural intervention.

Value pluralism hinges on an extension of democratic rubric, demanding as much democracy from the conduct of scientific endeavour as from the encounter among subjects of inquiry. The new science seeks to enhance democratic norms governing the interaction of the researchers and their relative roles (Funtowicz and Ravetz, 1993). The critical factor is a meta-political role on the part of scientists and social scientists. 


\section{References}

Anderson E, 1993 Value in Ethics and Economics (Harvard University Press, Cambridge, MA)

Arvai J L, Gregory R, McDaniels T L, 2001, “Testing a structured decision approach: value-focused thinking for deliberative risk communication” Risk Analysis 211065 - 1076

Bohman J, 1996 Public Deliberation: Pluralism, Complexity, and Democracy (MIT Press, Cambridge, MA)

Burgess J, Stirling A, Clark J, Davies G, Eames M, Staley K, Williamson S, 2007, "Deliberative mapping: a novel analytic-deliberative methodology to support contested science-policy decisions" Public Understanding of Science 16 299-322

Cohen J, 1989, "Deliberative democracy and democratic legitimacy", in The Good Polity Eds A Hamlin, P Pettit (Blackwell, Oxford) pp 17-34

Douai A, 2009, "Value theory in ecological economics: The contribution of a political economy of wealth" Environmental Values $18257-284$

Dryzek J S, 1987 Rational Ecology: Environment and Political Economy (Blackwell, New York)

Dryzek J S, 1990 Discursive Democracy: Politics, Policy, and Political Science (Cambridge University Press, Cambridge)

Dryzek J S, 1995, "Political and ecological communication" Environmental Politics 413 - 30

Dryzek J S, 2000 Deliberative Democracy and Beyond: Liberals, Critics, Contestations (Oxford University Press, Oxford)

Dryzek J S, Berejikian J, 1993, "Reconstructive democratic theory” American Political Science Review $8748-60$

Dryzek J S, Niemeyer S, 2006, "Reconciling pluralism and consensus as political ideals" American Journal of Political Science $50634-649$

Failing L, Gregory R, Harstone M, 2007, "Integrating science and local knowledge in environmental risk management: a decision-focused approach" Ecological Economics 64 $47-60$

Funtowicz S O, Ravetz J R, 1993, "Science for the post-normal age " Futures 25739 - 755

Gregory N, Gregory R, 2010, "A values-based framework for community food choices" Environmental Values 1999 - 119

Gregory R, 2000, "Valuing environmental policy options: a case study comparison of multiattribute and contingent valuation survey methods" Land Economics 76151 - 173

Gregory R, 2002, "Incorporating value trade-offs into community-based environmental risk decisions" Environmental Values $11461-488$

Gregory R, Failing L, 2002, "Using decision analysis to encourage sound deliberation: water use planning in British Columbia, Canada" Journal of Policy Analysis and Management 21 $492-499$

Gregory R, Slovic P, 1997, “A constructive approach to environmental valuation” Ecological Economics 21175 - 181

Gregory R, Wellman K, 2001, "Bringing stakeholder values into environmental policy choices: a community-based estuary case study" Ecological Economics $3937-52$

Gregory R, Lichtenstein S, Slovic P, 1993, "Valuing environmental resources: a constructive approach" Journal of Risk and Uncertainty 7177 - 197

Gregory R, McDaniels T, Fields D, 2001, "Decision aiding, not dispute resolution: creating insights through structured environmental decisions" Journal of Policy Analysis and Management 20 $415-432$

Gregory R, Fischhoff B, McDaniels T, 2005, "Acceptable inputs: using decision analysis to guide public policy deliberations" Decision Analysis 2 4-16

Gutmann A, Thompson D, 1996 Democracy and Disagreement (Belknap Press, Cambridge, MA)

Gutmann A, Thompson D, 2004 Why Deliberative Democracy? (Princeton University Press, Princeton, NJ)

Habermas J, 1984 The Theory of Communicative Action I: Reason and the Rationalization of Society (Beacon Press, Boston, MA)

Holland A, 1997, “The foundations of environmental decision-making" International Journal of Environment and Pollution $7483-496$

Howarth R B, Wilson M A, 2006, "A theoretical approach to deliberative valuation: aggregation by mutual consent" Land Economics $821-16$

Jacobs M, 1997, "Environmental valuation, deliberative democracy and public decision-making institutions", in Valuing Nature?: Ethics, Economics and the Environment Ed. J Foster (Routledge, London) pp $211-231$ 
Jorgensen B, 2009, "Social learning and the economic valuation of environmental impacts: a real contribution or a missed opportunity?" in Climate Change Responses in Regional Australia: Social Learning and Adaptation Eds J Martin, M Rogers, C Winter (VURRN Press, Victoria) pp $240-255$

Keeney R, 1992, Value-focused Thinking: A Path to Creative Decisionmaking (Harvard University Press, Cambridge, MA)

Lo A Y, Spash C, 2011, "Deliberative monetary valuation: in search of a democratic and value plural approach for environmental policy?", MPRA paper 30002, http://mpra.ub.uni-muenchen.de/ 30002/1/MPRA_paper_30002.pdf

McDaniels T L, Gregory R, Fields D, 1999, "Democratizing risk management: successful public involvement in local water management decisions" Risk Analysis 19 497-510

McDaniels T L, Gregory R, Arvai J, Chuenpagde R, 2003, "Decision structuring to alleviate embedding in environmental valuation" Ecological Economics $4633-46$

Macmillan D C, Hanley N, Lienhoop N, 2006, "Contingent valuation: environmental polling or preference engine?" Ecological Economics $60299-307$

Munda G, 1995 Multicriteria Evaluation in a Fuzzy Environment: Theory and Applications in Ecological Economics (Physica-Verlag, Heidelberg)

Munda G, 2006, "Social multi-criteria evaluation for urban sustainability policies" Land Use Policy $2386-94$

Myhr A I, 2010, "The challenge of scientific uncertainty and disunity in risk assessment and management of GM crops" Environmental Values 19 7-31

National Research Council, 2008 Public Participation in Environmental Assessment and Decision Making (National Academies Press, Washington, DC)

Nerlich B, 2010, “Climategate': paradoxical metaphors and political paralysis” Environmental Values $19419-422$

Niemeyer S, Spash C L, 2001, "Environmental valuation analysis, public deliberation, and their pragmatic syntheses: a critical appraisal" Environment and Planning C: Government and Policy $19567-585$

Norton B G, Noonan D, 2007, “Ecology and valuation: big changes needed” Ecological Economics 63 $664-675$

O'Hara S U, 2001, "The challenges of valuation: ecological economics between matter and meaning", in The Economics of Nature and the Nature of Economics Eds C J Cleveland, D I Stern, R Costanza (Edward Elgar, Cheltenham, Glos) pp 89 - 110

Proctor W, Drechsler M, 2006, "Deliberative multicriteria evaluation" Environment and Planning C: Government and Policy $24169-190$

Renn O, 1999, "A model for an analytic-deliberative process in risk management" Environmental Science and Technology 33 3049-3055

Renn O, Webler T, Wiedemann P, 1995 Fairness and Competence in Citizen Participation: Evaluating Models for Environmental Discourse (Kluwer Academic, Dordrecht)

Sagoff M, 1998, "Aggregation and deliberation in valuing environmental public goods: a look beyond contingent pricing" Ecological Economics 24213 - 230

Satterfield T, 2001, "In search of value literacy: suggestions for the elicitation of environmental values" Environmental Values 10331 - 359

Spash C L, 2007, "Deliberative monetary valuation (DMV): issues in combining economic and political processes to value environmental change" Ecological Economics 63690 - 699

Spash C L, 2008, "Deliberative monetary valuation and the evidence for a new value theory" Land Economics $84469-488$

Spash C L, 2009, "Editorial: the new environmental pragmatists, pluralism and sustainability" Environmental Values 18253 - 256

Spash C L, 2010, "Censoring science in research officially" Environmental Values 19141 - 146 
Conditions of use. This article may be downloaded from the E\&P website for personal research by members of subscribing organisations. This PDF may not be placed on any website (or other online distribution system) without permission of the publisher. 